\title{
Automatic Watering Using Soil Moisture Sensor
}

\author{
Bernardo A. Pangilinan ${ }^{1}$, Allen N. Maroma \\ ${ }^{1}$ College of Industrial Technology, Bulacan State University, Philippines \\ ${ }^{2}$ College of Industrial Technology, Bulacan State University, Philippines
}

\begin{abstract}
Background/Objectives: In recent years studies were done to determine the relationship of water content of the soil and its electrical resistivity, devices of different application can be construct using these relationship. The following applications benefitted from these findings like automatic water irrigation, soil moisture test for construction and watering system using soil moisture sensor. Methods/Statistical analysis: This study took advantage of the feature of microcontroller to sense varying resistance and controlling the solenoid water valve. The device is equipped with soil moisture sensor that varies its resistance depending on the conductivity of the soil. When the weather is to hot and the soil is dry, the resistance of the soil increases, if the soil is moist resistance of the soil decreases. Findings: The specific value of resistance was set in the microcontroller that signifies the need to water the plant using solenoid water valve. The controller will automatically open the gate valve of the water source, if the set resistance for watering was reached by the sensor. Improvements/Applications: Since water continuously enters the soil, it changes the resistivity of the soil. When the sensor reaches a resistance set in the microcontroller this will trigger the gate valve to close and signifies wet condition of the soil.
\end{abstract}

\section{Index Terms}

Microcontroller, Resistance, Solenoid Valve and Sensor

\author{
Corresponding author : B.A. Pangilinan \\ bernardo.pangilinan@bulsu.edu.ph \\ - Manuscript received February 1, 2020 \\ - Revised February 17, 2020 ; Accepted March 20, 2020 \\ - Date of publication March 31, 2020 \\ (C) The Academic Society of Convergence Science Inc. \\ 2619-8150 @ 2019 IJASC. Personal use is permitted, but republication/redistribution requires IJASC permission.
}




\section{INTRODUCTION}

The study was conceptualized by the interest of the researcher in finding ways to communicate plants to people. The question is there any way that plants can send a message to people for their need of water and to absorbed essential minerals to maximize growth. The idea was conceptualized when the researcher conduct a simple experiment, equipped with multi-tester probe set in the mode of resistance measurement injected the probe into the pot with a plant in it. Initially, the resistance reading is quite high then the researcher started to pour water in the pot the reading leads lower resistance value. This simple experiment ignited the idea to develop a controller that will control the flow of water in the gate valve based from the sense resistivity of the soil moisture sensor.

The researcher conducts this study to lessen the effect of drought in plants and vegetables especially when the farmers are not around to perform watering. The study will help the farmers and gardeners for automatically watering the plants and vegetables. It saves water and effort on the part of the farmers in watering the plant. In using this device, soil moisture sensor will sense if the soil is dry, if the soil is dry it means that the resistance of the soil is high. The soil moisture sensor will send this information to Arduino, the LCD display will indicates that the soil is dry, then, it will trigger now the water gate valve to open the passage so the water will come out to the gate valve and using water sprinkler the water will be distributed to the plants. The LCD display will indicates that the water sprinkler is on. When the soil moisture sensor sense that the soil is wet and reach the certain resistance that is needed by the plants the soil moisture sensor will send this information to Arduino, then it will automatically close the water gate valve. The LCD display will indicates that the soil is wet and the water sprinkler is off.

This study was conducted to resolve the main problem of properly watering the plants based from the sense conductivity of the soil. Existing methods were timer based methods which eventually water the plants in regular interval. This process cannot determine whether the plants or vegetables really need water due to the absence of water moisture sensing. Too much water is bad for the plants and the less of it is not good for the plants.

\section{Methods}

The study uses the descriptive method of research, using the findings from previous studies and existing devices in this field. The inputs are literature from previous studies, existing devices and interview from practitioners. The process involves a development of the circuits and mechanisms for automation of watering plants by sensing soil resistance using soil moisture sensor. The study also used evaluation instrument in measuring the functionality of the device.

The main objective of this study is to design and fabricate "Automatic Watering using Soil Moisture Sensor" to lessen drought the effect of drought in plants and vegetables. It will greatly benefit farmers and gardeners by automating the watering of plants and vegetables. It will also save water for watering because a specific resistance was set that triggers the water valve to shut-off.

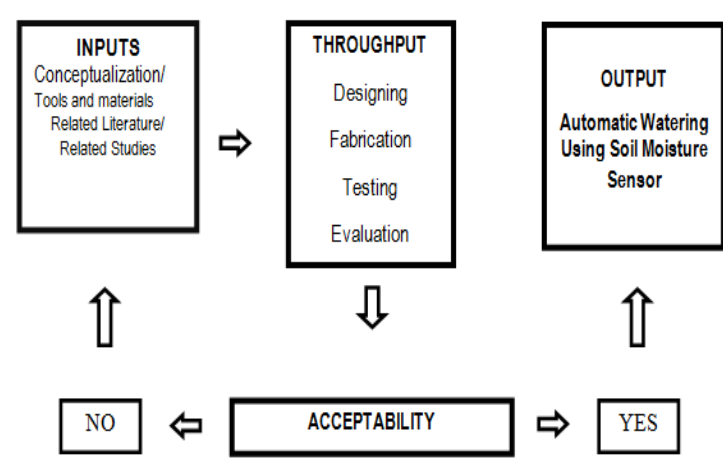

Fig. 1. Conceptual Model of the study.

The study started with the search of existing device suited to solve the problem of automatic watering of plants, there are system using the weight sensor for opening and closing the water valve. In this study the researcher uses soil moisture sensor in sensing the conductivity of the soil. The water valve is connected to the water source and being controlled by the microcontroller. Designing the control of the system consist of accepting values of soil condition which are the dry and wet condition of the soil. During the dry condition, the valve will be open and water flow from the source and sprinkled to the soil. During the wet condition, the valve will be close so water could not flow from the source to the sprinkler. These are all being controlled by the microcontroller. The wet and dry conditions are also display in the LCD display of the device. These conditions were also sense by the soil moisture sensor. The sensitivity of the system could also be adjusted using a potentiometer attached to the control module The microcontroller operates at 5 Volts dc from the regulator source.. The study focuses more on the possibility of controlling the flow of water and sensing the soil condition but does not have precise knowledge on the specific resistivity of soil that needed to be watered. The device was tested and validated its functionality by farmers and gardeners within the area. 


\section{RESUlTS AND DiscusSiON}

\section{A. Project Description}

The Automatic Watering Using Soil Moisture Sensor was designed to prevent the soil to dry and monitor the moisture of the soil. This device controls the watering of plants to avoid harmful effect of drought and too much watering of plants and vegetables. The device has a built-in power supply which converts 220 Volts -ac to 12 Volts-dc and regulated to 5-volts the needed power to run the microcontroller, sensor, and LCD display. The water gate valve is operated by a relay powered by 12 -volts power supply. The input sensor is a soil moisture sensor and a potentiometer directed both to the Gizduino Microcontroller. The output of the system is the LCD display for monitoring of soil condition and the water control valve for allowing water to flow from the source to the sprinkler.

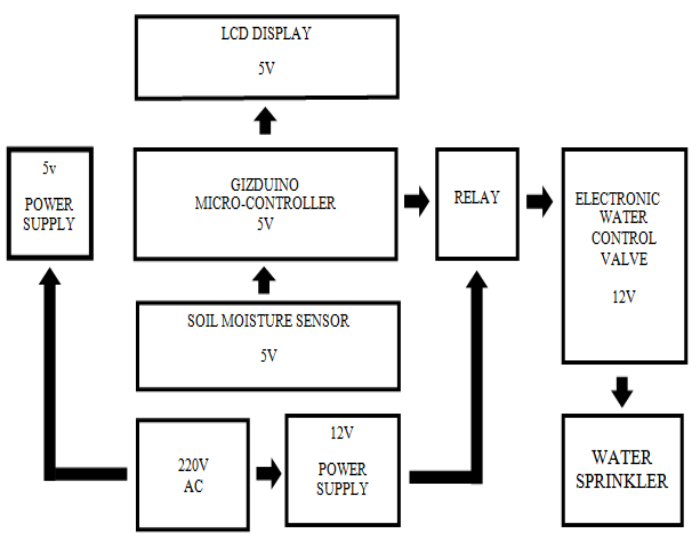

Fig. 2. Block Diagram of the Device

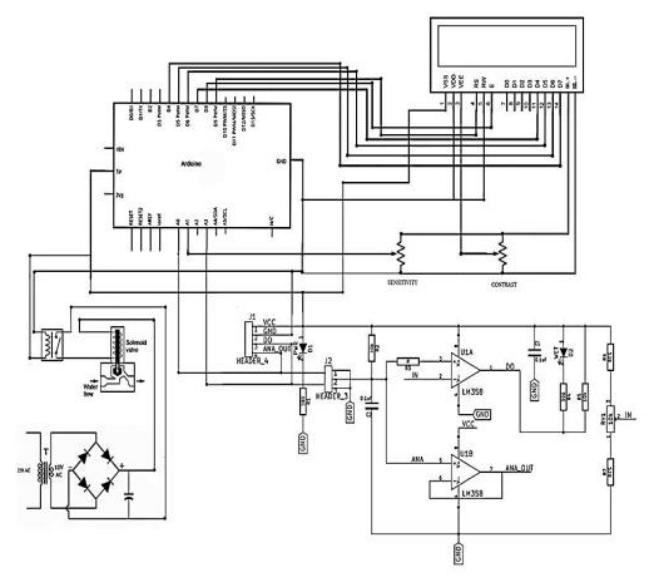

Fig. 3. Schematic Diagram of the Device

The Automatic Watering using Soil Moisture sensor has the capability to maintain and monitor the moisture of the soil. It can maintain the water supply to the farm. Automatic Watering using Soil Moisture sensor has the ability to function 12 hours a day. It also has an LCD Display to monitor if the soil is wet or dry. The device had limitation because it can only test the moisture of the soil not the specific nutrients.

A group of evaluators composed of farmers and gardeners were requested to evaluate the acceptability of the project in terms of the following criteria: (a) Physical feature, (b) Durability, (c) Portability, (d) Cost of Development, (e) Functionality,(f) Workmanship, (g) Reliability, (h) Safety and (i) Maintainability.

Table 1. Summary of MeAn SCORES FOR the AcCePtability/Evaluation OF THE PROJECT

\begin{tabular}{|c|c|c|}
\hline CRITERIA & MEAN & I N T E R P R E T A T I O N \\
\hline Physical feature & 4.29 & 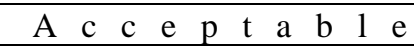 \\
\hline Durability & 4.16 & 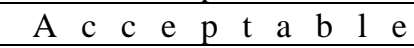 \\
\hline Portability & 4.53 & Highly Acceptable \\
\hline Cost of development & 4.26 & $\mathrm{~A}$ c c e p t a b l e \\
\hline Functionality & 4.63 & Highly Acceptable \\
\hline Workmanship & 4.59 & $\mathrm{Highly}$ Acceptable \\
\hline Reliability & 4.66 & Highly Acceptable \\
\hline Safety & 4.25 & 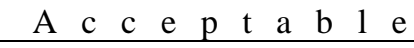 \\
\hline Maintainability & 4.36 & 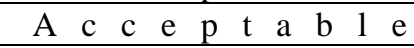 \\
\hline Overall Mean & 4.41 & A $\quad c \quad c \quad e \quad p \quad t \quad a$ \\
\hline
\end{tabular}

Rating Scale:

4.5 - 5.0 Highly Acceptable

$3.5-4.4$ Acceptable

$2.5-3.4$ Undecided

1.5 - 2.4 Moderately Unacceptable

1.0 - 1.4 Highly Unacceptable

\section{CONCLUSION}

On the basis of the result of evaluation, the following conclusions were derived:

1. The water sprinkler system will automatically turn on and off through the soil moisture sensor.

2. The sprinkler system consumption of water is lesser than watering the plants manually and saves more time in visiting the soil from time to time.

3. The cost of the materials in producing the device is reasonable.

4. The device is easy to use and it is eco-friendly.

\section{RECOMMENDATIONS}

The following recommendations were given by the researcher based on the observation, evaluation, and conclusion of the project. 
1. The device can use solar power for the source of electricity.

2. The $12 \mathrm{DCV}$ solenoid valve can replace with a $220 \mathrm{ACV}$ water gate valve.

3. GSM module for notification via Text message to the operator or consumer.

4. The device can use heat sensor for alternative sensing material of temperature of the soil.

\section{ACKNOWLEDGMENT}

The author wishes to extend his sincere appreciation to the administration of the Bulacan State University for its unwavering support to all its faculty researchers. Further he also would like to thank his family for their unconditional love.

\section{REFERENCES}

[1] Famiglietti et al. (1999). Ground-based investigation of soil moisture variability within remote sensing footprints during the Southern Great Plains. Hydrology Experiment, 6,1839-1851

[2] Larson et al, (2008). Use of GPS receivers as a soil moisture network for water cycle studies. GEOPHYSICAL RESEARCH,35, 65-85

[3] Rosnay et al.(2006). A long term field campaign experiment for soil moisture and land surface processes remote sensing. Remote Sensing of Environment. Office National d'Etudes et de Recherches Aérospatiales. Research, 102, 377-389

[4] Studies: Qui H (2006). Validation of Presumed Linear Relation between Surface Temperature Gradient and Soil Moisture Content. Civil and Environmental Engineering Department, 351, 421-477.

[5] Grayson and Western (1998). Spatial correlation of soil moisture in small catchments and its relationship to dominant spatial hydrological processes. Research Centre for Catchment Hydrology and Centre for Environmental Applied Hydrology, 286, 113-134.

[6] Schmugge et al.( 1980). From near-surface to root-zone soil moisture using an exponential filter: an assessment of the method based on in-situ observations and model simulations. Department of Civil and Environmental Engineering, 1324-1325.

[7] Blanchard et al. (1981). Surface Soil Moisture Estimation Using Passive Microwave Radiometer Data. Atmospheric and Climate Sciences Group Earth and Climate Science Area, 453-459.

[8] Arya et al. (1983) On the estimation of soil moisture profile and surface fluxes partitioning from sequential assimilation of surface layer soil moisture. Department of Civil and Environmental Engineering, 220, 86-103. 